\title{
Women's journey of recovery from sexual assault trauma : a grounded theory Part 2
}

\author{
SE Duma, PhD \\ Senior Lecturer, Division of Nursing and Midwifery, University of Cape Town \\ JN Mekwa, PhD \\ Professor, Division of Nursing and Midwifery, University of Cape Town \\ LD Denny, PhD \\ Professor, Division of Nursing and Midwifery, University of Cape Town
}

\section{Correspondence address:}

Dr. Sinegugu E. Duma

University of Cape Town

Division of Nursing and Midwifery

F45, Old Main Building

Groote Schuur Hospital

Observatory, 7925

Tel : (02) 406-6401

Fax : (021) 406-6323

E-mail : Sinegugu.duma@uct.ac.za

\section{Abstract: Curationis 30(4): 12-20}

The purpose of the study was to explore and analyse the journey of recovery which is undertaken by women who have been sexually assaulted, with the aim of discovering the grounded theory of recovery from sexual assault within the first six months following the event of rape. The main research question was: 'What is the journey of recovery that is undertaken by women within the first six months following sexual assault?' Another question that developed during data collection and data analysis was 'What is the meaning that women attach to recovery?'

The findings are discussed under the eight concepts or categories and the context and the intervening conditions that influence the journey of recovery from sexual assault trauma. Refer to part 1 article. These are complemented with abstracts of data from the participants' voices and the related discussions.

The developed theory highlights the process and the interconnectedness of the different stages of what the women experience in their journey of recovery from sexual assault trauma.

\section{Introduction}

The purpose of this article is to describe women's journey of recovery from sexual assault trauma. It is a theory of recovery from sexual assault trauma which was discovered and constructed through inductive and deductive analysis of data which was grounded on the ten women's descriptions of their journey from sexual assault, using Strauss and Corbin $(1990,1998)$ guidelines as a framework for conducting data analysis and other complementary qualitative research procedures in order to enhance the data analysis process and improve the trustworthiness of the data analysis process. The relevant excerpts from the participants' data are used to highlight the origins of the concepts of the theory.

The purpose of the study was to explore and analyse the journey of recovery which is undertaken by women who have been sexually assaulted, with the aim of discovering the grounded theory of recovery from sexual assault within the first six months following the event of rape. The main research question was: 'What is the journey of recovery that is undertaken by women within the first six months following sexual assault?' Another question that developed during data collection and data analysis was 
'What is the meaning that women attach to recovery?'

The findings are discussed under the eight concepts or categories and the context and the intervening conditions that influence the journey of recovery from sexual assault trauma. Refer to the part one article.

\section{The concepts of the theory and their origins}

\section{Sexual assault trauma}

Sexual assault trauma was identified as the first concept of the theory of recovery from sexual assault. The main category of the concept of sexual assault trauma, 'mental paralysis', is an immediate state in which the participant finds herself during the sexual assault event and immediately thereafter.

Mental paralysis was derived from two terms, "mental" which is defined as "of the mind" and "paralysis" with a figurative meaning relating to a state of utter powerlessness (The Concise Oxford Dictionary of Current English, 1964: 760, 880).

In the excerpt below, one participant illustrates 'a state of mental paralysis' as follows:

"My husband was still lying with his hands and feet tied. I did not even think of untying him. I just lay there for some time. I could not move or think. My whole body was just heavy....The next thing, I heard my husband who had finished untying himself, I don't know how, instructing me to dress. I then realised that there was nothing wrong with my body, I could move."

Another participant described the same experience as follows:

"I just lay there motionless. He came back and said, 'Good, you are still here'. He continued from where he left, Sine. He did his thing until he was satisfted. He left me there and disappeared. I stood there naked for some time..."

\section{Awakening}

The concept 'awakening' was derived from the definition of awakening which comes from the word 'awaken'. Awaken means: to cease to sleep, becoming conscious of or being aroused from sleep. The figurative meaning of the term 'awaken' is "to become active" (The Concise Oxford Dictionary of Current
English, 1964: 81). The latter meaning was use to construct the concept 'awakening' in the theory. The subcategories under this concept include self-blaming, blaming God for allowing rape to happen, guilty feelings and being blamed, allowing someone to take control, conflict of beliefs, seeking help and selective disclosure, i.e. determining what to tell about the event of rape, how much to tell, who to tell and when to tell about the event of rape. Selective disclosure can also mean deciding whether to tell or not to tell at all.

During awakening, the woman realises the repercussions of rape, and starts considering what the incident of rape means to her. She appears not to be in total control of what is going on, and is likely to be dependent or to rely on the other people's decisions or advice.

Self-blaming and blaming God are illustrated in the excerpts below:

"After that I arrived at home blaming myself, regarding myself as useless. I should have gone straight home and not gone to the party with Pamela lfriend, not her real name]. I should not have slept at her place. I kept asking myself why God allowed this to happen to me."

Another participant expressed her selfblame as follows:

"I had thought that he will leave me after the rape, worse, we had just got married for 2 months. I was blaming myself for what happened to us, and I felt that he [husband] was really going to leave me for that and would not love me at all."

Blaming God is illustrated in the following excerpt:

"I know that my thoughts are bad, because I still ask myself why He allowed this to happen to me. Do you think I am confused?"

For a participant who discovered after rape that she was HIV-positive, selective disclosure was very important, and she knew exactly who should be told which information and how. She selected what or how much to tell the members of her family and those of her live-in boyfriend: "I have not told my sister about the HIV results and we [she and her boyfriend] have also decided not to tell my mom who is in Eastern Cape about the rape. I am not ready to tell my sister and her husband (who are like parents to me here in Western Cape) about HIV results.
In fact even the rape thing, I would have preferred to keep it to myself. I think one can deal with such things personally before getting others involved. Okay! Now that they know, I have told them not to tell mom. I also asked my partner not to tell his family about any of this."

A statement by a participant whose case of rape was in the media, including the national and local newspapers and local radio stations, indicated that she would have preferred the matter to be kept within the family as follows:

"My story was laid all over the newspapers, I had no say about who I wanted to tell about it. Everybody just knows about it in the whole community. I am not complaining, but if I had a choice, I would have had it differently. Even my younger siblings read about it on their own, I would have preferred to tell them myself."

Seeking help during the phase of awakening was influenced by the decisions of other people, who either gave advice to the participant or took charge or control of the situation and arranged for what they thought was the best for the participant:

An example of the decisions taken by the health professionals on behalf of the participant was referral for counselling, as illustrated below:

"Another thing, I went to the counselling session at Litha Park as I was referred by the nurse at the centre. I did not know anything about counselling, but I went as suggested by the nurse".

Another example describes the social worker's involvement in assisting the participants to prepare for the court hearings:

"When I told the nurse at centre that I was afraid to talk about rape in court, she said she would get me someone to help me. I did not know that she could really do that for me. They just took care of all my needs."

\section{Pragmatic acceptance}

Pragmatic acceptance was derived from two words, namely to 'pragmatise' and 'acceptance'. To pragmatise is to represent as real or rationalise. Acceptance is the word derived from 'accept', which means to receive as adequate, allowing truth of, believe or take responsibility for favourable acceptance (The Concise Oxford 
Dictionary of Current English, 1964:955, 8).

In the current theory, 'pragmatic acceptance' represents categories and subcategories in which the participants rationalise why the event of rape happened to her, in order for her to come to terms with the sexual assault or accept its reality. The subcategories under the concept or category 'pragmatic acceptance' include the following: giving acceptable reasons for why the event of rape occurred, such as rape being God's will, rape as an experience that happens to good as well as bad people, rape happening to believers and nonbelievers alike, and rape as a tool of war.

This rationalisation was illustrated in different ways by participants in their narratives. Examples are given below.

"Since I told myself that it was God's will and God's plan that I went there, maybe had the guy found Pamela Ifriend, not her real namel alone there, he would have raped and killed her and stolen her gun, it has been easy for me to accept what has happened and to move on. That person did not want to rape me. He wanted Pamela and he was going to kill her. Maybe it was God's will that I saved Pamela's life because we are fellow worshippers."

Another participant described how she had to accept the act or event of rape in order to move on with her life:

"I can say that I am at peace with what happened to me. Although the thoughts keep coming back, but I just told myself that I must be at peace with it. I keep telling myself to forgive and forget about it. That is the only way I can move on".

Later (at the end of week 24), the same participant was asked about the forgiving she had referred to at four weeks. She gave an explanation that indicated that the initial forgiving and forgetting was about pragmatic acceptance. She said:

"Earlier I was referring to forgiving the act that has happened to me, like in acceptance kind of. It's only when you accept that such a thing has happened and you cannot change it, that you are able to move on."

\section{The turning point}

According to the Concise Oxford Dictionary of Current English, 1964 (1404), the 'turning point' is a point in place, time or development at which decisive change occurs. This category was identified as a core category of the theory of women's journey of recovery from sexual assault trauma. Its subcategories included the following: woman's definition of herself as a survivor or victim of sexual assault, taking control and responsibility about what goes on, symbolic actions, and the face of the rape victim versus the face of the survivor.

Although the 'turning point' is placed within a specific point within the theory, in reality the 'turning point' can occur at different levels or points during the woman's journey of recovery, because the participants are individuals and their conditions and circumstances are not the same.

The 'turning point' was identified as a core category, because it provided an account of the variation in different participants' journey of recovery from sexual assault trauma. The determining factor for the direction taken at the 'turning point' is the woman's taking of control and responsibility for her own healing. The forward, positive and clockwise direction is a feature of those who take control of the situation and the responsibility for their own healing, irrespective of the presence or absence of supportive structures in their environment. The backward, negative and anti-clockwise directions are a feature of those women who remain victims and are not in control of the circumstances in their environment.

The women's description of their 'turning point', taking responsibility and defining themselves as a survivor, is illustrated below:

"In reality Sine, I can say everything that goes with healing starts with you as a raped person. You accept that rape has happened and nobody can take it from you. You can attend all counselling sessions, but if you think of yourself as a victim and have not accepted what happened and decided to move on, then, you won't heal. Healing starts when you decide that 'I am not a victim anymore, I am a survivor. I am above what happened to me'. That helped to turn things around and move on."

Another woman explained her 'turning point' and taking responsibility for healing as follows:

"I realised that for healing to occur, I needed to tell myself that such a thing has happened and I could not change it. I decided to continue living my life the way I wanted and not to let the rape thing stop me from living, or living as a rape victim all my life. I then decided to take control of everything I did to help me heal."

Physical appearance was described as an important factor in determining the 'turning point' towards the positive direction of healing, as follows:

"I took the money that was paid by the tenants for last month's rent and bought myself a pair of shoes and did my hair at the salon. I had no nice shoes and I was going to attend the session with the social worker. I wanted to look good because I have decided that I am moving on with my life and the social worker was going to help me do that".

In the absence of positive support from family, one participant found support from community members, and she explained that this was important in determining the 'turning point' for her: "My friends and people of the community have really supported me because they were even there at Wynberg Court. Even now, they are collecting contributions for hiring transport to court on the $17^{\text {th }}$ of March. When I heard that they were singing and having placards in my support, I was really touched by their deed. I became determined to continue with the case no matter what."

The fear of HIV infection can influence the 'turning point' in a positive or negative way. The participant below described how her fear that her HIV blood results would come out positive was delaying her progress, until she decided to do something about it, when she got to a 'turning point'. In the first narrative she described her concern about the HIV results. In the second narrative, she describes what she did at the 'turning point'.

"If the second HIV results come back negative in March, I will know that the whole thing is over. If they come back positive, Yoooo! That will be a disaster really! My husband will not accept that at all. There is always that fear at the back of my mind, but I do not dwell on it. My happiness is short-lived indeed."

Three months later, she related how she decided not to go for the blood results 
anymore, and how that marked her 'turning point' and helped her move from victim status:

"I did not go for the second HIV results in March. The fear of finding out that the results had turned positive was killing me. I decided that in order to move on, I needed to do something. I had to take control, I was continuously a victim offear, fear of becoming positive! I just decided not to go for results and any other tests. Since that decision, I felt in control and not being controlled by that fear."

\section{Reclaiming what was lost}

'Reclaiming what was lost' was derived from the word 'reclaim' which is to win back or away from vice or savagery or waste condition (The Concise Oxford Dictionary of Current English, 1964: 1033) - what was lost through the event of sexual assault and immediately thereafter.

The subcategories that are related to the causal conditions of the concept 'reclaiming what was lost' included participants' recognition and acknowledgement of the aspects of self which were lost through the event of sexual assault and immediately thereafter, how the participant valued those lost aspects of her life, grieving for what was lost, the presence of the motivator that provides the impetus for active strategies in reclaiming that which was lost, such as a need for self-defence. From data analysis the lost aspects were interpreted as freedom to walk freely, loss of spiritual self, lost of trust for men, power of selfdefence, self doubt, doubting God's presence, and religious beliefs.

The participant below described that which was lost as the free-spirited self: "Even if he were to say he was sorry, I would tell him that he killed a part of me. I am not dead but that free-spirited person in me, a free person who believed in the goodness of other people, is no longer with me.... He killed that part of me which was free to walk around and talk to people, now I have to be aware of people around me, I have to be aware of a person coming from afar, and decide whether I have to turn back or do what ... .I mean there is a part of you that is lost, you become responsible about yourself and even other people's actions."

The following participant described what was lost as the sense of ability to defend oneself in the following response:
"It was like he ripped my inside out and I could not defend myself. Losing that power of self-defence was too much a loss to bear. I am now trying to regain that power of self-defence. I will consider myself healed once I can feel that sense of power back, like the ability to defend myself."

Another participant described what she had lost during the event of rape as her spiritual self or belief in God:

"Somehow I guess I doubted God's presence since the event of rape. The pastor helped me by telling me that I must not think like that. God never forsakes us. The fact that I was not killed shows that He is alive and protected me. ... Since I regained that spiritual sense and spiritual part of me, I felt better."

The participant below described her loss of trust in men in general, and what she had to do to regain that in the following response:

"It's like learning something new. I am learning to deal with a new experience. Learning how to trust men again. because not all men are the rapist, my brother-in-law, my boyfriend, my pastor, my male colleagues at work, are not bad guys. I have always known that, but I have to learn that again."

Another aspect of self that was lost and was worth fighting to regain was the sexual lives among couples. The first response is from a married woman who was raped in front of her husband, and how her husband "decontextualised" rape from sex:

"My husband told me that what he witnessed was not me having sex or making love to another man. He said that what he watched was not sex, but the violation of our rights as a married couple. He made me to understand that there is a difference for rape and sex. That helped both of us to view sex differently. We spoke about it before resuming our sex life and everything went well from the word go. We needed to talk about it in order to become a married couple and enjoy sex again. At least I needed to hear it from him."

The following participant explains how they had to "decontextualise" rape from sex after failure of attempts to have sex following the rape:

"Hmmmm! Basically we have not had sex as such. He might be waiting for me to be ready. It's been difficult to have sex with him. I guess it's me because we tried and it was so uncomfortable, I just could not do it. I kept on seeing the images of that day. I have this bad image. You know when a guy breathes, when they are aroused they basically have the same smell when they get excited. I just could not handle that smell. I just asked him to stop. I am not sure if he is now waiting for me to tell him whether it's okay to start. At the same time the little time we spend together, we end up talking about this man all the time. Basically our sex life went out with the rape itself."

\section{Defining own landmarks}

The concept of 'defining own landmarks' in the journey of recovery was constructed from the following words and their meaning: 'defining', which means to make clear or declare exact meaning (The Concise Oxford Dictionary of Current English, 1964: 319), and 'landmark', which means an object or event marking a stage in a process or a turning point in history (The Concise Oxford Dictionary of Current English, 1964: 677).

The concept 'defining own landmarks' was identified from different descriptions by the participants, relating what they would regard as recovering from sexual assault trauma and/or the meaning they attached to the experiences they were describing.

The categories and subcategories under 'defining own landmarks' of recovering from sexual assault trauma included the following: being able to talk about the event of rape without feeling pain; having a good appetite and weight gain; acknowledging the time needed for the grieving process; getting out of the grieving process; remaining HIV-negative and maintenance of negative HIV status; and readiness to confront the rapist and readiness to forgive him and restoration of 'blood' (health).

Being able to talk about the event of rape without feeling the same pain that one felt earlier when talking about it was reported as a landmark of recovering:

"I think I am healing well. I am now able to talk about this without feeling bad. When I talk about it, it's like I am talking about something that happened to me in my childhood or long ago. You know .... [silence and thinking] like when a successful person tells you about how 
he or she went to school without shoes, and how painful that was, without actually feeling that pain again. To me that is healing. That is, if I can talk about the pain that happened to me when I was raped without actually feeling that pain any more. You know, I was telling another woman I met at the clinic on our way back from the clinic about my rape story. She looked at me and said, but you do not look like you were raped and you do not even look like you felt the pain. Then I knew I am better now."

Another reported being able to talk about the event of rape and feeling no negative emotions as her landmark of recovering as follows:

"I know I am better now because I can talk about it to my friends without feeling embarrassed or ashamed. ... I feel alright now. It is not like when this first happened."

"Restoration of blood" (or health), appetite and weight gain were reported as another definition of the landmark of healing:

"I feel alright now, it's not like in the beginning, and I do not think about this thing the way I used to think before. During that time I used to think about it always. I was always not happy, even my weight, I just think, I saw myself losing weight. Now I have gained weight, I have returned to my blood [explained as health]. I lost appetite, but now, at least I eat, I don't have any problem."

In response to the researcher's comment about how the following participant was gaining weight, the participant demonstrated weight gain as a landmark for healing:

"Yes, I have noticed it [beaming with smiles]. It [weight] happens on its own. People say that it means I am dealing with the rape and the grieving period well. From what they say, then I know that it is a good sign. Others say it means that I am getting better. I can also feel it myself ... I think it goes with the healing of the heart."

The following participant also reported regaining her appetite, gaining weight and doing things that she used to do as positive landmarks of recovering in her journey of recovery from sexual assault: "I've gained back my appetite, it's coming back nicely. I did not like food, I found that after sometime the things I used to do are coming back, I started going out, doing window shopping, and all things that I could not do anymore since the rape. My life was - to go to work; come home; listen to the radio. At work, during lunch, I would sit alone, play games on my cell phone or listen to the music from my cell phone, but not talking to anyone. Now I join others during lunch, enjoy with them like before. I see that Maru [not real name] is back. I think that is healing for me."

Acknowledging the time needed for grieving and healing was also reported as defining the landmark of healing:

"From this time to that time, I need to grieve the loss of that part of me, if it takes me three months or longer, so be it. You should not put time limits. Give yourself time and space to move from one stage to the other. But I must say you need to give yourself time to grieve. It's only after you have gone through that stage that you get to another level which I think is healing".

Another participant spoke about time as a landmark of healing in the following statement:

"Time on its own is helping me with healing. I believe that time is healing... knowing that you will be healed completely after some time."

Knowing about her negative HIV status and maintaining it as negative throughout the subsequent tests was a landmark of recovering for another participant. At the end, she had to stop her relationship with her boyfriend in order to maintain her HIV-negative status, after reviewing his behaviour and finding it to be risky:

"Knowing that I am HIV-negative after the last test will be healing. For now I cannot put my life and my kids' life at risk. 'Cause if I go out, then I put myself at risk, including HIV and dying with AIDS. Who will look after my kids when I am dead?"

\section{Readiness for closure}

The concept of 'readiness for closure' was derived from the two words 'readiness' and 'closure'. 'Readiness' means willingness, and 'closure' means conclusion or bringing to or coming to an end (The Concise Oxford Dictionary of Current English, 1964:1028, 226).

The concept of 'readiness for closure' was coined as such because it was recognised that at the end of six months (the study period), the participants had not reached closure, although some of them described willingness for closure to happen. One study participant questioned the possibility of closure in the following comment:

"Saying I have put closure or healed fully....well in a way, yes, but I can't say fully 'cause I would not know how it feels to be fully recovered. For instance, I thought I was fine and have put all this behind me, until last week. I met this guy. He is the policeman who helped me on the day of the rape. He said 'Do you remember me? I met you there [pointing to the direction of the rape site five months agol. What happened to you? Suddenly I felt that jolt. It seemed as if the rape that happened that day was happening then. So, I guess there will always be those things that remind me. ...but besides that jolt, I am moving on well."

The readiness for closure had subcategories such as the desire to see justice done, willingness to see the rapist imprisoned and sentenced appropriately for what he did, and God doing something to the rapist or religious justice.

Based on the participants' voices on willingness or readiness for closure, it was concluded that readiness for closure is a reality for most women. The following statement describes readiness for closure:

"I think for purposes of closure, it is important to accept what has happened to you so that you can move on. You must be able to identify things that you are not yet ready to deal with."

Another participant who viewed future plans as closure commented as follows: "So, now that I think I have grieved enough for the loss of that part of me, I can concentrate on what I need to achieve for myself and my kids. I need to improve my education because I only have Matric Igrade 12 level of education]. If there is one positive thing that came out of this rape ordeal, it is that it gave me time to re-evaluate my life, what I need to do, what I do not need, and I am now more futureorientated."

Seeing justice done was another important category under 'readiness for closure':

"I wish he could be caught lby the police] and he could just say why he did 
it and apologise for it. That will make it much easier to forgive him. So what I did, 1 chose to just forget about his face and how it looked like. I realised that that worked for me because when the detective came to ask us to come and identify him, I refused because I realised that I have forgotten how he looked like."

This need for justice to be done was reported to be important not only to the women, but also their partners. Men took it as their responsibility to ensure that justice was done. That could be in the form of physical violence directed to the perpetrator:

"They [partner and brother-in-law] are both convinced that they will find the guy who did this to me through their connections. They will deal with him if they find him before the policemen do. Right now I think the police should get him first. Otherwise the two [partner and brother-in-law] will end up in jail for what they intend to do to him."

The partner of the following participant also wanted to see justice done and wanted to take justice into his own hands, as indicated in the following comment:

"He keeps saying 'f I knew this guy who did this to you, I could have long taken care of him! And I would feel much better. The fact that I do not know him, I walk down the streets, looking for someone I do not even know!' I am like, why do you bother? This revenge and anger creates problems for the two of us."

The community members also had a desire to see justice done, as explained in the accounts of two participants below: "The community members attend the court proceedings and when I heard that they were there outside singing, that served as a source of strength for me."

"Last week the women marched to the police station to complain about the rapist and they demanded that he be caught and dealt with by law."

In another case, the community took justice into their own hands because the legal system was seen to be failing, based on the fact that the perpetrator kept on getting out on bail:

"You know the person who raped me died about a month ago. He was caught on the other side busy with his hooligan ways. He was breaking into people's houses, raping women as usual. They caught him and they beat him up. Seemingly the police arrived. They took him to the day hospital. He was transferred to hospital. He died there."

A major observation made during data analysis, and inserted in different theoretical memos, was that all participants reported the rape to the police. None of them withdrew the case, even when they were pressurised to do so by the family or others. This observation confirmed the participants' desire to see justice done.

Another observation was that the sexual assault management team, including the legal and social services, all worked together in the management of sexual assault survivors, ensuring that forensic evidence was collected, physical examination was conducted and documented accurately, history and statements about the incident of rape were documented accurately, and participants were well informed of the progress of the case to the court of law to ensure that justice was done.

\section{Returning to self}

The concept of 'returning to self' was constructed from the two words 'return' and 'self'. 'Return' means come back. 'Self' means persons' own individuality or essence, which is all that makes a thing what it is. 'Self' also means a person as object of introspection or reflective action (The Concise Oxford Dictionary of Current English, 1964: 1066,1148).

Subcategories of the concept of 'returning to self' include the following: participants defining themselves as a survivor or 'old' self rather than as victims, refusing to be defined by sexual assault, being strong in order to return to the old self, wanting my life back, selection of helpful strategies to return to self, be an ideal self, and acknowledging triggers that would always be a reminder of sexual assault trauma.

The participant's description below demonstrates conscious decisions taken in order to achieve the goal of returning to self:

"I chose to ignore whatever was not helping me in a way of grieving or dealing with the situation. I knew what I wanted, I wanted to have my life back, and I had to concentrate on that all the time".

The following statement also relates to the participant's main goal in embarking on the journey of recovery from sexual assault trauma:

"That became my main goal, to be strong and try to return to my old selffor myself and for him as my husband".

Refusal to be identified as anything associated with sexual assault, whether a sexual assault victim or sexual assault survivor, was described by one participant as follows:

"I do not look at myself or define myself as $Z$ [o [not real name] the rape victim, or Zo, the rape survivor. I am Zo for all my other attributes. What happened to me does not define who I am. It is something that happened just like all the mishaps which happened in my life which I want to forget. That is what I want to be, myself!"

Acknowledgement of the presence and intrusive nature of the memories of the event of rape in their daily lives was highlighted by the following comments: These thoughts come like when someone talks about any crime that happened in the neighbourhood. For instance, if there was a break-in in one of the neighbours. To me it just feels like it was the same person and no one else [laughing]

Certain reminders of the event of rape were identified as follows:

"Just a look at all the scars I suffered through his hands reminds me of everything."

\section{Discussions and Recommendations}

The findings revealed that the ultimate goal of the women's journey of recovery was returning to self. As a result, the women embarked on a series of conscious and subconscious actions to return to the self. The series of conscious and unconscious actions are depicted in the concepts of the theory of the women's journey of recovery from sexual assault trauma discovered and developed from descriptions by the women of their social world after the event of sexual assault. These concepts include awakening, pragmatic acceptance, turning point, reclaiming what was lost, defining own landmarks for healing, and readiness for closure.

Although returning to self is an ultimate 
goal, the women also had a clear understanding that the journey of recovery will not lead to the same person that one was before the event of rape, but to a new self. Awareness and understanding of this is evidenced by the women's acknowledgement of what they had lost during the event of sexual assault, the grieving process that they underwent for the aspects they had lost, as well as the lessons they had learnt from the incident of sexual assault. Different authors attest to the loss of certain aspects of self from the event of sexual assault, including one's inner sense of gender identity and control of their lives and thoughts (Bletzer \& Koss, 2006; Brison, 2002).

Lunt (2002: 33) supports the findings on the presence of the ultimate goal of recovery. He states that for recovery to occur, one needs to have a goal, a direction, an inspiration, faith or hope. The findings indicate that those participants who identified their ultimate goal of recovery early in their journey were able to take control and move forward, irrespective of the intervening conditions.

The findings also revealed that women identify their own landmarks of healing or recovery. Interpretation of the landmarks of recovery identified, together with the ultimate goal of returning to self, was the women's meaning of recovery from sexual assault.

Recovery from sexual assault trauma as a phenomenon, is a personal journey. Hence, each participant had to identify her own ultimate goal and define her own landmarks of healing or recovering. These findings are supported by the Recovery Movement within the mental health fraternity's definition of recovery. The Recovery Movement conducted research to reach consensus on the definition of recovery, finding that recovery is "a deep personal, unique process of changing one's attitudes, values, feelings, goals, skills and or roles." Recovery was also reported to involve the development of new meaning and purpose in one's life (Jacobson, 2003: 378). The same definition of recovery is described by Davidson, o'Connell, Thandora, Staeheli \& Evans (2006: not paged).

The major breakthrough in and the significance of the findings of this study was the women's identification of their own landmarks of recovering. For the first time, black women's voices regarding what they consider important in their health and recovery from sexual assault trauma, and their views regarding their bodies and their needs in intimate relationships, were analysed and interpreted in research. These voices have been used to construct new and legitimate knowledge about what black women consider to be important in their lives, their wellness, their bodies and their health and recovering from sexual assault trauma - as opposed to what the Western world has defined as the 'ideal' for all women.

One particularly interesting finding in the category "defining own landmarks of healing" was that relating to weight gain following the sexual assault event. The participants' view on regaining one's appetite and of weight gain following sexual assault trauma was identified as a sign of a positive journey of recovery. It was even described by one participant as "the healing of the heart". This is in contrast to the Western view, which regards weight gain following sexual assault as an eating disorder (Liburd, Anderson, Edgar \& Jack, 1999: 382). In the current study, the good appetite and weight gain were viewed positively and associated with healing or recovering.

The difference in black and white women's views regarding weight gain and eating disorders are well founded in literature. In their study, Liburd et. al (1999: 382), found that the black women participants indicated that a middle-tolarge body was healthier. Other studies have shown differences between young black and white women in attitudes to eating, body aesthetics and body dissatisfaction. These reported that white women had an affinity for thinness and more frequently engaged in dieting and eating disorders than black women (Aruguete, DeBord, Yates \& Edman, 2005: 328; Franko \& Striegel-Moore, 2002: 975 ).

The black women's perception of weight gain as a landmark of healing or recovering warrants recognition as a contribution to development of new and legitimate knowledge about what seems to be important to black women's definition of healing or recovering from sexual assault. Service providers should take this into cognisance when planning, implementing or evaluating secondary interventions for survivors of sexual assault.

The participants highlighted that reclaiming their sexual relationship with their partners was influenced by mutual agreement between the woman and her partner. The mutual agreement was achieved by separating ("decontextualise") the sexual act from rape. Reassurance from their partners that nothing had changed in terms of their feelings for them was another strategy that the couples used to reclaim their sexual relationships. These strategies helped them to regain their sexual functioning. The interpretation was that regaining sexual functioning was faster among those in stable and supportive relationships.

The above findings are supported by previous studies by Burgess and Holmstrom (1979:1278), who also discovered that partner support facilitated faster general recovery. However, these findings contradict some of the findings by Gilbert and Cunningham (1986: 71), who reported sexual dysfunction within the first six months period following sexual assault. Sexual dysfunction symptoms reported after the sexual assault event included abstinence and decreased or increased sexual activity within the six-month period (Gilbert \& Cunningham, 1986: 71).

The discovery regarding the mutual agreement about resumption of sexual relations between the participants and their intimate partners is of great significance. This is a contribution to new and legitimate knowledge about black women and the control of their sexual lives. It is new knowledge because it is in contrast to what has been the belief by Western feminists about black women's control of their sexual lives.

The Western feminists' literature paints black women as being sexually constrained, ignorant, poor, uneducated, tradition-bound, victimised, lacking control of their bodies and sexuality, and lacking freedom to make decisions regarding sexual relationships. In contrast the image of the white woman has always been painted as educated, modern, having control over their own bodies and sexuality, and having freedom to make their own decisions (Hutchison, 1998: not paged). Most Western feminist literature does not mention or recognise and acknowledge the emergence of a 
black woman who is in control of all aspects of her life, including the sexual aspects. The findings of the current study show that black women are assertive about their sexual needs and able to stand up against many forms of abuse and oppression, including sexual abuse.

The current study illustrated the fact that participants were in control of their sexual lives and in equal partnerships with their intimate partners. The participants who returned to sexual relations immediately after the assault indicated that they discussed the matter with their partners. Some participants described how their partners helped them to see sexual assault for what it was, and to separate it from making love, in order to resume their sexual lives. The participants made the decision to re-engage in sexual relations with their partners and were not forced or coerced. However, more research is needed on the new developments regarding the emerging young black woman and her responses to sexual assault. This is a challenge for both black and Western feminist researchers as well as Black Western feminist researchers.

The emergence of the assertive black woman identified in the study is, however, not without challenges. The main challenge is that there is no certainty regarding the black man's acceptance of his new assertive partner. In the current study, a serendipitous observation of the black man's attitude manifested itself in the reported negative and irritating attitude and behaviour of some of the intimate partners of the participants. The participants reported that their partners took the matter of sexual assault too personally and became vindictive, wanting to avenge themselves for what had been done to their possession (partner). One referred to her partner's need for revenge as a "personal vendetta". The participants were asked by their partners to provide elaborative descriptions of the perpetrator, so that the avenging partners could go and look for them. At least two participants were made to take a drive through the streets with their partners to look for the perpetrator. Such attitudes and behaviours were reported as affecting the journey towards recovery negatively.

More importantly, such partner behaviours were interpreted as indirect secondary victimisation of the women, because being forced to think about the face of the perpetrator to the point of being able to provide his description to the partner was like being forced to relive or re-experience the actual act of rape. The fact that the participants reported refusal to engage in such exercise indicated that they regarded these behaviours as unwanted, unsupportive and unhelpful in their journey of recovery.

The findings about the partners' attitudes and behaviours could also highlight the effect that the sexual assault trauma had on the participants' partners. The partner's ego gets bruised when his partner is sexually violated. In that case, the sexual violation is not only to the woman, but is also directed to him as a violation of his property or object. Vulnerability to being viewed as a sexual object or the property of men at home, on the streets and in the society at large is a challenge to both black women and their Western sisters. This is indirectly perpetuated by the media through the use of women in advertisements intended to promote men's achievements.

More research is needed regarding the how black men are coping with the emerging assertive black woman, how black men are accepting their independent sisters, as well as how they are coping with the rape of their partners.

\section{The context and the intervening conditions influencing recovery}

The context and the intervening conditions that influence the journey of recovery from sexual assault trauma throughout the different steps were interpreted and grouped as follows:

1. Personal biographies, such as the participants' cultural and religious beliefs, values, experiences and fears - such as the fear of HIV infection from being sexually assaulted aspirations and personalities.

2 Supportive and non-supportive behaviours of significant others and service providers.

3. - Supportive and non-supportive environment, including family, community and society, as well as the health, legal and social system.

The presence or absence of one or more of these influences the journey of recovery from sexual assault for each individual differently.

An important finding among the consequences of the journey of recovery from sexual assault trauma was the participants' awareness that they will never be the same person they were before the experience of being sexually assaulted. They regarded that experience as part of their lives forever, although they were yearning for closure. Memories of the rape event were reported to be something that would remain with them all their lives. One participant related the sight of the scars of her healed wounds that were inflicted by the rapist as reminding her of the rape ordeal whenever she saw them. This is similar to what was reported by Winkler (2002) who is cited by Bletzer and Koss (2006: 5) as an "emotional tattoo" that will forever remain in one's remembrance.

Although the study took a period of six months for each participant, for most the pain of the sexual assault trauma was already a memory by the end of the study period. The event was no longer constantly on their mind. However, they reported that it was a memory that was easily triggered by anything that remotely resembled sexual violation, including any criminal behaviour.

\section{Conclusion}

The developed theory highlights the process and the interconnectedness of different stages of what the women experience in their journey of recovery from sexual assault trauma. The "women's journey of recovery from sexual assault trauma grounded theory" is an answer to the questions "What is the journey of recovery that is undertaken by women within the first six months following sexual assault?, and 'What is the meaning that women attach to recovery?'.

\section{References}

ARUGUETE, MS; DEBORD, KA; YATES, A \& EDMAN, J 2005: Ethnic and gender differences in eating attitudes among black and white college students, Eating Behaviours. 6(4). 328-336.

BLETZER, KV \& KOSS, MP 2006: "After-rape among three populations in the Southwest, a time for mourning, a time for recovery", Violence Against Women. 12(1), 5-29. 
BRISON, SJ 2002: After-math: Violence and the remaking of a self. Princeton, Princeton University Press.

BURGESS, AW \& HOLMSTROM, LL 1979: Adaptive strategies and Recovery from rape, American Journal of Psychiatry.136(10).1278-1282.

DAVIDSON, L; O'CONNELL, MJ; TONDORA, J; STAEHELI,M\&EVANS, AC 2006: Recovery in Serious Mental Illness: Paradigm Shift or Shibboleth? Unpublished Work

FRANKO,DL \& STRIEGEL-MOORE, RH 2002: The role of body dissatisfaction as a risk factor for depression in adolescent girls: are the differences Black and White?, Journal of Psychosomatic Research. 53(5), 975-983.

FRAZIER,P;TASHIRO,T; BERGMAN, M; STERGER, M, \& LONG, J 2004: Correlates of levels and patterns of positive life changes following sexual assault, Journal of Clinical Psychology. 72(1),19-30.

GII BERT, B \& CULLINGHAM,J. 1986: Women's post rape sexual functioning: Review and implications for counselling. Journal of Counselling and Development. 65, pp. 71-73.

HUTCHISON M 2006: Black and White Feminism, a Post Colonial Vision. http:// ergsum.uaemex.mx./noviembre98/ mireille.html. retrieved on 2-4-2006.

JACOBSON, N 2003: Defining Recovery: an interactionist analysis of mental health policy development, Wisconson 1996-1999, Qualitative Health Research. 13(3), 378-393.

LIBURD, LC; ANDERSON, LA, EDGAR, T \& JACK, L JR. 1999: Body size and body shape: perceptions of black women with diabetes, Diabetes Education. 25(3), 382-388.

LINCOLN, YS \& GUBA, EG 1985: Naturalistic Inquiry, Beverley Hills: SAGE Publishers.

LUNT, A 2002: A Theory of Recovery, Journal of Psychosocial Nursing.40(12), 33-39.

STRAUSS, A \& CORBIN, J 1990: Basics of qualitative research: Grounded theory procedures and techniques,
London: Sage.

STRAUSS A \& CORBIN J 1998: Basics of qualitative research: Techniques and Procedures for Developing Grounded Theory, 2nd ed, Thousand Oaks: SAGE.

\section{THE CONCISE OXFORD} DICTIONARY OF CURRENT ENGLISH,1964: $5^{\text {th }}$ Edition. Oxford: Oxford University Press. 